\title{
FONTES E PROPORÇÕES DE MATERIAIS ORGÂNICOS NA GERMINAÇÃO DE SEMENTES E CRESCIMENTO DE PLANTAS JOVENS DE GOIABEIRA ${ }^{1}$
}

\author{
FRANCISCO TOMAZ DE OLIVEIRA ${ }^{2}$, OSCAR MARIANO HAFLE ${ }^{2}$, VANDER MENDONÇA ${ }^{3}$, \\ JOSERLAN NONATO MOREIRA ${ }^{2}$, LUCIANA FREITAS DE MEDEIROS MENDONÇA ${ }^{4}$
}

RESUMO - Os diversos materiais orgânicos e as proporções usadas como substratos na produção de mudas de goiabeira podem fazer a diferença na qualidade final, trazendo benefícios ao produtor e ao meio ambiente. O objetivo da pesquisa foi avaliar o efeito de fontes e as proporções de materiais orgânicos na germinação de sementes e no crescimento de plantas jovens de goiabeira. O experimento foi realizado no período de setembro de 2010 a março de 2011, na Fazenda Experimental do Instituto Federal de Educação, Ciência e Tecnologia da Paraíba, Câmpus Sousa, localizado no Perímetro Irrigado de São Gonçalo, Município de Sousa, Paraíba. O delineamento experimental foi em blocos completos casualizados, em esquema fatorial $3 \times 4$ (esterco bovino, esterco ovino e húmus de minhoca, nas seguintes proporções: 0;20; 40 e 60\%), com quatro repetições e dez plantas por unidade experimental. As características avaliadas foram: comprimento da parte aérea, diâmetro do caule, massa seca da parte aérea, massa seca das raízes, massa seca total e os teores de macronutrientes ( $\mathrm{N}, \mathrm{P}, \mathrm{K}, \mathrm{Ca}, \mathrm{Mg}$ e $\mathrm{S}$ ) na massa seca da parte aérea. O esterco de ovino e o húmus de minhoca são as fontes orgânicas que proporcionam os mais altos valores médios para as características morfológicas avaliadas. A proporção de $40 \%$ do material orgânico, independentemente da fonte usada, favoreceu o crescimento das mudas de goiabeira. Proporções crescentes das fontes orgânicas no substrato provocam redução no teor de fósforo.

Termos para indexação: Psidium guajava, esterco, macronutriente, substrato.

\section{SOURCES AND PROPORTIONS OF ORGANIC MATERIALS ON SEED GERMINATION AND GROWTH OF GUAVA SEEDLINGS}

\begin{abstract}
The various organic materials and proportions used as substrates for the production of guava seedlings can make a difference in the final quality benefits to the producer and the environment. The experiment aimed at to evaluate the effect of sources and proportions of organic materials on seed germination and growth of guava seedlings. The experiment was carried out during the period of September 2010 to March 2011, in the Experimental Farm of the Instituto Federal de Educação, Ciência e Tecnologia da Paraíba, located in the São Gonçalo Irrigated Perimeter, Sousa-PB, northeastern Brazil. It was used a randomized complete-blocks experimental design, with the treatments arranged in a $3 \times 4$ factorial scheme (bovine manure, ovine manure and earthworm humus in the following proportions: 0, 20, 40 and $60 \% \mathrm{v} / \mathrm{v}^{-1}$ ), four replications, and ten plants per experiment unit. The evaluated traits were: shoot length, stem diameter, shoot dry mass, root system dry mass, total dry mass, and macronutrient (N, P, K, Ca, Mg and S) contents in shoot dry masses. The ovine manure and earthworm humus are organic sources that provide the highest averages to the evaluated morphological traits. Independently of the organic source added to the substrate, $40 \%$ of the organic matter favored seedlings growth. Increasing proportions of organic sources in the substrate causes reduction in phosphorus content.
\end{abstract}

Index terms: Psidium guajava, manure, macronutrient, substrate.

\footnotetext{
${ }^{1}$ (Trabalho 034-13). Recebido em: 04-01-2013. Aceito para publicação em: 09-08-2013.

${ }^{2}$ Professor, D.Sc. do Instituto Federal de Educação, Ciência e Tecnologia da Paraíba, Câmpus Sousa (IFPB- Sousa-PB), Perímetro Irrigado de São Gonçalo, Sousa-PB. CEP 58800-970- Sousa-PB. email: tomazdeoliveira@bol.com.br, omhafle@yahoo.com.br, moreiragronomo@hotmail.com.

${ }^{3}$ Professor D.Sc. do Departamento de Ciências Vegetais da Universidade Federal Rural do Semiárido. BR 110, Km 47, Bairro Presidente Costa e Silva, CEP 59628-680- Mossoró, RN-Brasil E-mail: Vander@ufersa.edu.br. Bolsista de Produtividade do CNPq- Nível 2 ${ }^{4}$ Doutoranda do curso de pós-graduação em Fitotecnia da Universidade Federal Rural do Semiárido. BR 110, Km 47, Bairro Presidente Costa e Silva, CEP 59628-680- Mossoró-RN-Brasil E-mail: lucisfreitas@hotmail.comr. Bolsista da CAPES
} 


\section{INTRODUÇÃO}

A utilização de resíduos orgânicos aparece como alternativa para diminuir as despesas da adubação química (CUNHA et al., 2005). Assim, a matéria orgânica surge como um componente importante na formulação de substratos (COSTA et al., 2005), pois esses materiais misturados ao solo contribuem com os atributos físicos, favorecendo o fornecimento dos nutrientes necessários ao desenvolvimento de raízes e de mudas (NEGREIROS et al., 2004).

$\mathrm{Na}$ propagação de plantas, o substrato é tido como um dos fatores de maior influência na qualidade final das mudas (CASAGRANDE JÚNIOR et al., 1996). Sendo bom, este deve possuir características químicas, físicas e biológicas capazes de criar um ambiente favorável à germinação e ao desenvolvimento da nova planta, além de ser disponível nas proximidades do local de produção e apresentar baixo custo (MENDONÇA et al., 2003; TOSTA et al.,2010).

Várias pesquisas sobre a utilização de fontes orgânicas no desenvolvimento de mudas são observadas na literatura, com destaque para Correia et al.(2005), Lima et al. (2006), Zietemann e Roberto (2007), Dias et al. (2009) e Mesquita et al. (2012). No entanto, verifica-se, principalmente, no contexto da agricultura agroecológica, a necessidade de estudos aprimorados sobre o uso de fontes orgânicas de origem animal e suas respectivas proporções na composição do substrato, capazes de atender às exigências quanto ao bom desempenho agronômico dos porta-enxertos de goiabeira.

Para a produção de mudas de goiabeira, é muito utilizado o método assexuado, sendo a enxertia um deles. No entanto, praticamente inexistem estudos com porta-enxertos para a cultivar Paluma na região Nordeste, sendo que o uso desta cultivar poderá minimizar problemas de incompatibilidade entre porta-enxerto e enxerto.

Esses estudos são fundamentais para fomentar o desenvolvimento da agricultura sustentável no Nordeste brasileiro, pois valoriza os insumos produzidos nas pequenas e médias propriedades que necessitam de práticas para o manejo mais eficiente do esterco como adubo orgânico.

Com isso, o objetivo deste trabalho foi avaliar o efeito de fontes e proporções de materiais orgânicos na germinação de sementes e no crescimento de plantas jovens de goiabeira.

\section{MATERIAL E MÉTODOS}

O experimento foi instalado e conduzido no viveiro de mudas da 'escola-fazenda' do Instituto Federal de Educação Ciência e Tecnologia da Paraíba, Câmpus de Sousa (IFPB-Sousa), Perímetro Irrigado de São Gonçalo, Sousa-PB (6 $0^{\circ} 0^{\prime} 33$ ” S; $38^{\circ} 17^{\prime} 54^{\prime \prime}$ W e $\left.264 \mathrm{~m}\right)$, no período de setembro de 2010 a março de 2011.

Na produção das mudas, foram usadas como material propagativo sementes de goiabeira (Psidium guajava L.), da cultivar Paluma, provenientes de frutos sadios e maduros. Os frutos foram cortados ao meio, separando-se polpa e semente. As sementes foram lavadas em água corrente sobre peneira de malha fina para a eliminação dos resíduos de polpa e casca. A seleção foi efetuada através de catação manual, para descarte de sementes pequenas e danificadas. A secagem foi realizada em local arejado e sombreado, durante o período de três dias.

O delineamento experimental utilizado foi em blocos completamente casualizados, com os tratamentos distribuídos em esquema fatorial $3 \mathrm{x}$ 4, com quatro repetições. A parcela experimental foi composta por dez plantas. Os tratamentos resultaram da combinação de três fontes orgânicas (esterco bovino, esterco ovino e húmus de minhoca) e quatro proporções dessas fontes $(0 ; 20 ; 40$ e $60 \%$, correspondendo a 0,$00 ; 0,36 ; 0,72$ e $1,08 \mathrm{~L}$ recipiente $\left.{ }^{-1}\right)$ em mistura ao solo e areia $\left(3: 1 \mathrm{v} \mathrm{v}^{-1}\right)$.

Antes da instalação do experimento, amostra do solo usado no preparo dos substratos foi enviada para análise química, no Laboratório de Análise de Solo, Água e Planta do IFPB-Sousa, cujos resultados foram: $\mathrm{pH}$ (água 1:2,5) $=6,50 ; \mathrm{P}=89,17 \mathrm{mg} \mathrm{dm}^{-3} ; \mathrm{K}$ $=0,26 \mathrm{cmol}_{\mathrm{c}} \mathrm{dm}^{-3} ; \mathrm{Ca}=4,80 \mathrm{cmol}_{\mathrm{c}} \mathrm{dm}^{-3} ; \mathrm{Mg}=1,50$ $\mathrm{cmol}_{\mathrm{c}} \mathrm{dm}^{-3} ; \mathrm{Na}=0,08 \mathrm{cmol}_{\mathrm{c}} \mathrm{dm}^{-3} ; \mathrm{Al}=0,00 \mathrm{cmol}_{\mathrm{c}}$ $\mathrm{dm}^{-3} ; \mathrm{H}+\mathrm{Al}=1,3 \mathrm{cmol} \mathrm{dm}^{-3} ; \mathrm{SB}=6,64 \mathrm{cmol}^{-3} \mathrm{dm}^{-3}$; $\mathrm{CTC}=7,94 \mathrm{cmol}_{\mathrm{c}} \mathrm{dm}^{-3} ; \mathrm{V}=83,63 \% ; \mathrm{MO}=4,65 \mathrm{~g}$ $\mathrm{kg}^{-1}$ e $\mathrm{CE}=0,04 \mathrm{dS} \mathrm{m}^{-1}$. As fontes orgânicas foram analisadas no laboratório de Análises de Solo, Água e Planta da Embrapa - Semiárido, Petrolina-PE, cujos resultados se encontram na Tabela 1.

Após o preparo dos substratos, os recipientes (sacos plásticos de 1,8 L) foram preenchidos manualmente e conduzidos ao viveiro, permanecendo uma semana sob irrigações diárias antes de receberem as sementes.

A semeadura foi realizada colocando-se três sementes por recipiente, na profundidade de 1 a 2 $\mathrm{cm}$, cobrindo-as com fina camada de substrato e casca de arroz para conservar a umidade e favorecer a germinação. A emergência ocorreu 20 dias após a semeadura (DAS), e o desbaste foi realizado aos 40 
DAS, deixando-se a plântula vigorosa e centralizada.

As irrigações foram diárias (manhã e tarde), fornecendo um volume de água suficiente para elevar a umidade do substrato próximo à capacidade de campo. As plantas invasoras foram eliminadas manualmente, assim que as mesmas surgiam. Durante o período de condução do experimento, não foi realizada nenhuma adubação em cobertura.

Aos 180 DAS, foram analisadas as seguintes características: comprimento da parte aérea - CPA (obtido pela distância entre a região do colo e a gema apical do ramo principal); diâmetro do caule - DC (obtido pela medição das plantas a oito centímetros acima do colo, com o auxílio de um paquímetro digital); massa seca da parte aérea MSPA (obtida pela separação da raiz através de um corte na região do colo, acondicionadas em sacos de papel, etiquetadas e secadas em estufa a $65^{\circ} \mathrm{C}$, com circulação forçada de ar até peso constante); massa seca das raízes - MSR (procedimento adotado foi o mesmo da MSPA); massa seca total - MST (resultante da soma dos valores da massa seca da parte aérea e massa seca das raízes), e teores de nitrogênio $(\mathrm{N})$, fósforo $(\mathrm{P})$, potássio $(\mathrm{K})$, cálcio $(\mathrm{Ca})$, magnésio $(\mathrm{Mg})$ e enxofre $(\mathrm{S})$ na massa seca da parte aérea (obtidos em amostras moídas em moinho tipo Wiley e enviadas ao laboratório de Solo, Água e Planta da Embrapa - Semiárido-PE, para a determinação dos teores de macronutrientes).

Os resultados foram submetidos à Análise de Variância (ANOVA) ao nível de 0,05 de significância, e as médias, comparadas pelo teste de Tukey, a 0,05 de probabilidade, através do programa computacional - SISVAR (FERREIRA, 2000). Para efeito do fator proporções orgânicas, foi realizada Análise de Regressão Polinomial.

\section{RESULTADOS E DISCUSSÃO}

Não houve interação significativa entre as fontes orgânicas e as proporções para as características CPA, DC, MSPA, MSR, MST, e teores de N, P e K, verificando-se, assim, efeitos isolados dos fatores analisados.

Os maiores valores de comprimento da parte aérea das mudas de goiabeira foram 44,86 $\mathrm{cm}$ (aos 120 dias), 64,76 cm (aos 150 dias) e 73,25 cm (aos 180 dias), nas proporções 37,61; 38,84 e $39,47 \%$, respectivamente (Figura 1). Este aumento no crescimento decorre da maior disponibilidade de nutrientes, principalmente $\mathrm{N}, \mathrm{Pe} \mathrm{Ca}$, proporcionado pelo aumento crescente de materiais orgânicos adicionados ao substrato, promovendo maior absorção destes nutrientes pelas plantas. Resultados semelhantes foram obtidos por Trindade et al. (2000), Góes et al. (2011) e Mesquita et al. (2012), estudando o comportamento de materiais orgânicos na produção de mudas de goiabeira, tamarindeiro e mamoeiro, respectivamente. Estes autores obtiveram função quadrática ajustada a essa variável como o aumento das proporções de materiais orgânicos na produção de mudas.

Para o comprimento da parte aérea, em função das fontes orgânicas, verifica-se que os substratos fertilizados com esterco ovino e húmus de minhoca apresentaram os maiores valores de crescimento, são estatisticamente semelhantes entre si, mas superam o esterco bovino aos 120 e 150 DAS. Aos 180 DAS, o esterco ovino apresentou o melhor resultado (Tabela 2). Casagrande Júnior et al. (1996) e Correia et al. (2005), avaliando altura de mudas de araçazeiro e de porta-enxertos de goiabeira verificaram que o húmus de minhoca proporcionou os melhores resultados para esta variável.

Foi observado aumento do diâmetro do caule com o aumento das proporções de material orgânico, até o valor máximo de $5,65 \mathrm{~mm}$ na proporção de $46,39 \%$, decrescendo, em seguida, até a maior proporção adicionada ao substrato (Figura 2). Essa redução pode ser resultado da quantidade de nutrientes na composição do substrato, causando um eventual efeito depressivo ou consequência da maior retenção de umidade devido à maior quantidade de matéria orgânica com redução no teor de oxigênio. Essa mesma tendência foi verificada por Pereira et al. (2010) e Mesquita et al. (2012) ao estudarem mudas de tamarindeiro e mamoeiro, respectivamente, formadas à base de diferentes proporções de material orgânico.

Entre as fontes orgânicas, foram verificadas diferenças significativas com o húmus de minhoca, registrando o maior valor, superando em 3,51\% o esterco ovino e $9,77 \%$ o esterco bovino (Tabela 2). Correia et al. (2005) e Pinto et al. (2007), ao estudarem mudas de goiabeira, verificaram o melhor desempenho do húmus de minhoca no aumento desta variável.

Nas massas secas da parte aérea, raízes e total, verifica-se que os maiores valores calculados foram: 12,$55 ; 3,46$ e 16,02 g planta $^{-1}$ nas proporções de 40,$19 ; 36,93$ e $39,65 \%$, respectivamente (Figura 3 ). A quantidade de massa seca encontrada nos tecidos de mudas tem grande importância como indicativo da qualidade, pois reflete seu crescimento em função da quantidade de nutrientes absorvidos (FRANCO et al., 2007).

Para o teor de nitrogênio na parte aérea, foram observados aumentos com as proporções até 
o valor máximo de $22,27 \mathrm{~g} \mathrm{~kg}^{-1}$ obtido na proporção $53,50 \%$, correspondendo a um aumento de $69,74 \%$ em relação ao valor obtido na proporção $0 \%$ (Figura 4). Esse aumento é resultado da eficiência do adubo orgânico, bem como da disponibilidade desse elemento à planta. Resultado similar foi encontrado por Lima et al. (2006) em pesquisas feitas com mudas de aceroleira desenvolvidas sob fontes e proporções de material orgânico.

Para o teor de fósforo, houve diminuição linear da concentração com o aumento das proporções de material orgânico (Figura 5). Esse resultado pode ser explicado pela eficiência na absorção e aproveitamento do fósforo do solo pela goiabeira como reflexo de sua adaptação a solos de baixa fertilidade (SAMARÃO; MARTINS, 1999) e/ou consequente efeito de diluição, por ocorrer maior produção de massa seca com aumento da proporção de adubo orgânico.

Quanto ao teor de potássio, observa-se que as proporções orgânicas no substrato aumentaram a concentração do elemento na MSPA das mudas, com os valores adequando-se ao modelo de regressão linear crescente (Figura 6). Esse resultado é semelhante ao observado por Pereira et al. (2010) na parte aérea de mudas de tamarindeiro. Para Chaves e Dias (1996) a matéria orgânica existente nos adubos orgânicos contém teores de potássio quase na totalidade da forma trocável, o que contribui para sua fácil absorção pelo sistema radicular.

Interação significativa entre as fontes orgânicas incorporadas ao substrato e suas proporções foram observadas nos teores de cálcio, magnésio e enxofre na parte aérea das mudas de goiabeira (Tabela 3). Desdobrando-se a interação, observou-se que o teor de cálcio na parte aérea foi influenciado tanto pelas fontes orgânicas, quanto pelas proporções. Os maiores teores de cálcio foram observados nas proporções de $0 \%, 20 \%$ e $60 \%$ na fonte esterco bovino, de $0 \%$ e $20 \%$ na fonte esterco ovino e de $0 \%$ na fonte húmus de minhoca (Tabela 3). Lima et al. (2006), pesquisando o desenvolvimento de mudas de aceroleira, encontraram teores foliares máximos de cálcio $\left(26,8 \mathrm{~g} \mathrm{~kg}^{-1}\right)$ na proporção de $80 \%$ de húmus de minhoca em mistura de $20 \%$ de terra na composição do substrato.

Estes resultados, quando comparados com as concentrações crescentes de potássio em função do aumento das proporções (Figura 6), corroboram os de Bernardi et al. (2000), quando afirmam que o cálcio tem baixa mobilidade dentro da planta e compete pelos mesmos sítios de absorção que o $\mathrm{K}$, que, em altas concentrações, reduz a absorção do Ca pelas plantas, demostrado efeito de inibição competitiva.
Para magnésio, os maiores teores foram observados na proporção de $60 \%$ na fonte esterco bovino e de $40 \%$ e $60 \%$ na fonte húmus de minhoca, não se verificando diferença significativa para a fonte esterco ovino (Tabela 3). Pode-se constatar que as fontes orgânicas proporcionaram teores de $\mathrm{Mg}$ diferentes em cada proporção, sendo o húmus de minhoca o que promoveu os maiores teores do referido nutriente, independentemente da proporção. Esse resultado pode ser atribuído à quantidade de nutrientes presentes no húmus de minhoca, assim como de sua baixa relação $\mathrm{C} / \mathrm{N}$, onde o $\mathrm{Mg}$ mineralizado pode ser absorvido, contribuindo para os maiores teores do nutriente na parte aérea da muda. Lima et al. (2009) observaram que o húmus de minhoca evidenciou os melhores resultados para teores de magnésio nas folhas de mudas de gravioleira, diferindo significativamente das demais fontes.

No teor de enxofre, constata-se que houve efeito das fontes e proporções sobre o conteúdo do nutriente na parte aérea das plantas. Os maiores teores foram observados nas proporções de $20 \%$, $40 \%$ e $60 \%$ na fonte esterco bovino e de $0 \%$ e $20 \%$ na fonte esterco ovino. Não se verificou efeito significativo para o teor de $\mathrm{S}$ na fonte húmus de minhoca (Tabela 3). Estes resultados expressam a maior disponibilidade de $\mathrm{S}$ nas fontes esterco bovino e ovino, favorecendo a absorção do nutriente pela planta. 


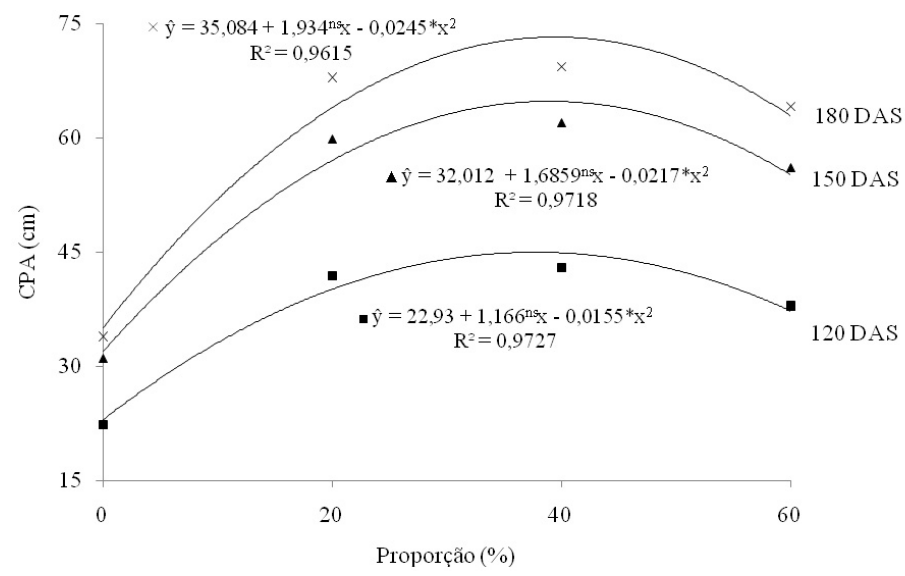

FIGURA 1 - Comprimento da parte aérea (CPA) das mudas de goiabeira em função de diferentes proporções de matéria orgânica incorporada ao substrato. Sousa-PB, IFPB, 2012.

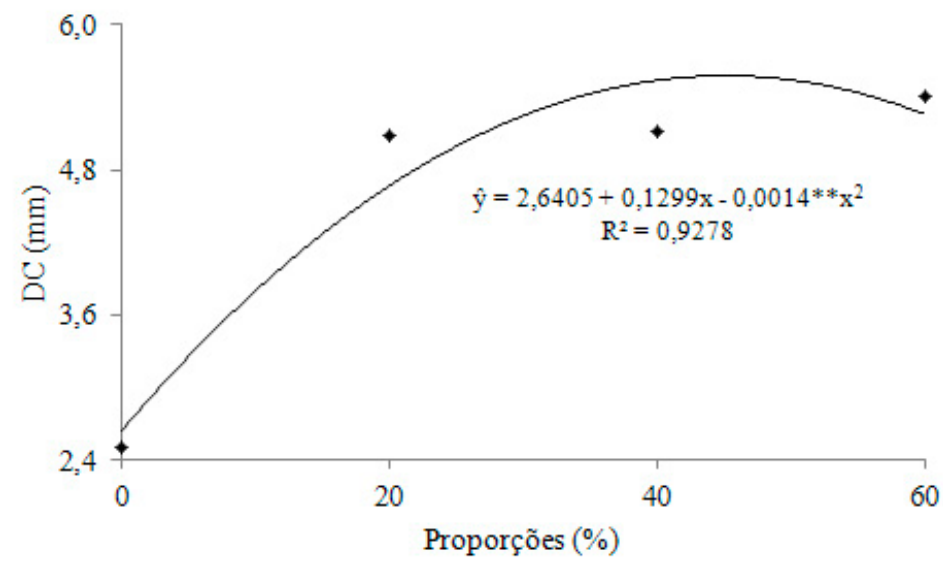

FIGURA 2 - Diâmetro do caule (DC) das mudas de goiabeira, aos 180 DAS, em função de diferentes proporções de matéria orgânica incorporada ao substrato. Sousa-PB, IFPB, 2012.

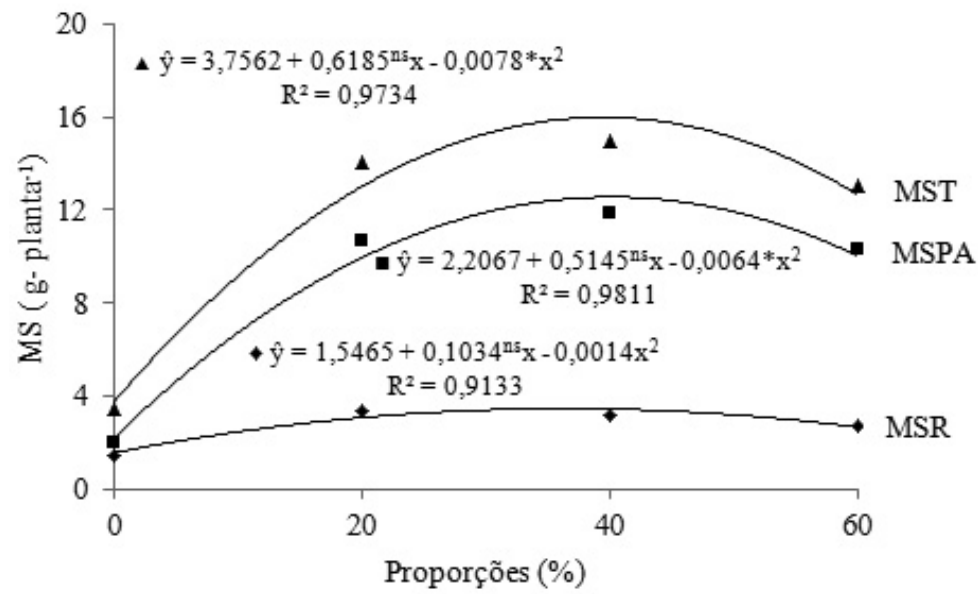

FIGURA 3 - Massa seca da parte aérea (MSPA), massa seca das raízes (MSR) e massa seca total (MST) das mudas de goiabeira, aos $180 \mathrm{DAS}$, em função de diferentes proporções de matéria orgânica incorporada ao substrato. Sousa-PB, IFPB, 2012. 


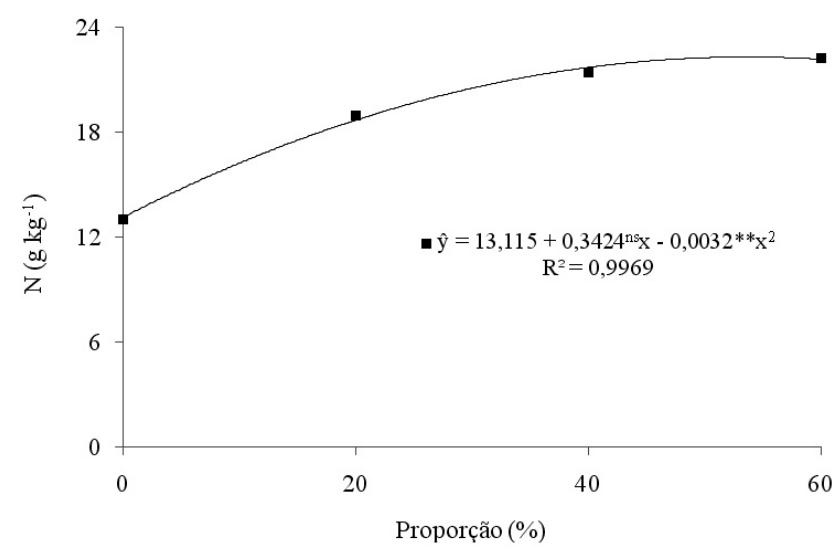

FIGURA 4 - Teor de nitrogênio $(\mathrm{N})$ na massa seca da parte aérea das mudas de goiabeira, aos 180 DAS, em função de diferentes proporções de matéria orgânica incorporada ao substrato. Sousa-PB, IFPB, 2012.

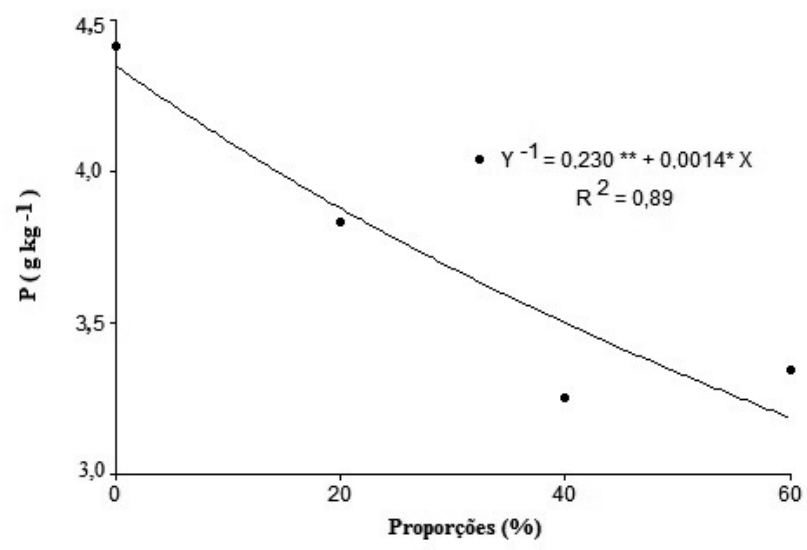

FIGURA 5 - Teor de fósforo (P) na massa seca da parte aérea das mudas de goiabeira, aos 180 DAS, em função de diferentes proporções de matéria orgânica incorporada ao substrato. Sousa-PB, IFPB, 2012.

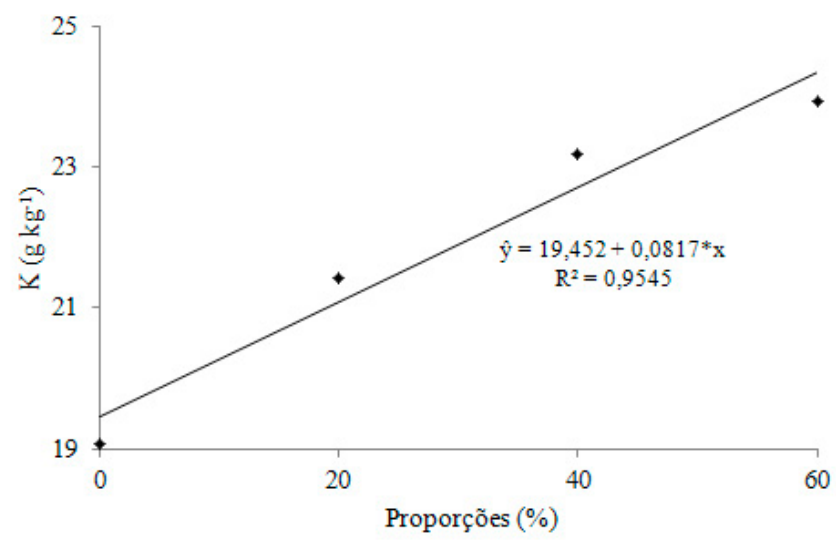

FIGURA 6 - Teor de potássio (K) na massa seca da parte aérea das mudas de goiabeira, aos 180 DAS, em função de diferentes proporções de matéria orgânica incorporada ao substrato. Sousa-PB, 
TABELA1-Análise químicadas fontes orgânicasusadasnacomposiçãodossubstratos. Sousa-PB,IFPB, 2012.

\begin{tabular}{llllrrrrrrr}
\hline Fontes Orgânicas & $\mathrm{CO}$ & $\mathrm{N}$ & $\mathrm{P}$ & $\mathrm{K}$ & $\mathrm{Ca}$ & $\mathrm{Mg}$ & $\mathrm{S}$ & $\mathrm{C} / \mathrm{N}$ & $\mathrm{C} / \mathrm{P}$ & $\mathrm{C} / \mathrm{S}$ \\
\hline & $\%$ & & $\ldots \ldots \ldots \ldots \ldots \ldots \ldots \ldots \ldots \ldots .$. \\
\end{tabular}

TABELA 2 - Comprimento da parte aérea (CPA) e diâmetro do caule (DC) das mudas de goiabeira em função de diferentes fontes orgânicas incorporadas ao substrato. Sousa-PB, IFPB, 2012.

\begin{tabular}{lcccc}
\hline \multicolumn{1}{c}{ Fontes Orgânicas } & \multicolumn{3}{c}{ CPA $(\mathrm{cm})$} & DC \\
\cline { 2 - 4 } & 120 & 150 & 180 & $(\mathrm{~mm})$ \\
\hline Esterco bovino & $31,77 \mathrm{~b}^{*}$ & $47,94 \mathrm{~b}$ & $55,27 \mathrm{~b}$ & $4,30 \mathrm{~b}^{*}$ \\
Esterco ovino & $38,97 \mathrm{a}$ & $55,64 \mathrm{a}$ & $61,79 \mathrm{a}$ & $4,56 \mathrm{ab}$ \\
Húmus de minhoca & $38,05 \mathrm{a}$ & $53,18 \mathrm{a}$ & $59,28 \mathrm{ab}$ & $4,72 \mathrm{a}$ \\
\hline DMS & 3,18 & 4,56 & 4,45 & 0,33 \\
CV $(\%)$ & 10,11 & 10,05 & 8,73 & 8,35 \\
\hline
\end{tabular}

* Médias seguidas pela mesma letra, nas colunas, não diferem entre si, pelo teste de Tukey, a 0,05 de probabilidade.

TABELA 3 - Teores de cálcio $(\mathrm{Ca})$, magnésio $(\mathrm{Mg})$ e enxofre $(\mathrm{S})$ na massa seca da parte aérea (MSPA) das mudas de goiabeira, aos $180 \mathrm{DAS}$, em função de diferentes fontes e proporções de matéria orgânica incorporada ao substrato. Sousa-PB, IFPB, 2012.

\begin{tabular}{|c|c|c|c|}
\hline Proporções (\%) & \multicolumn{3}{|c|}{ Fontes Orgânicas } \\
\hline & Esterco bovino & Esterco Ovino & Húmus de minhoca \\
\hline & \multicolumn{3}{|c|}{$\mathrm{Ca}\left(\mathrm{g} \mathrm{kg}^{-1}\right)$} \\
\hline 0 & $17,25 \mathrm{aB}^{*}$ & $30,75 \mathrm{aA}$ & $27,74 \mathrm{aA}$ \\
\hline 20 & $13,70 \mathrm{aC}$ & $26,71 \mathrm{aA}$ & $20,59 \mathrm{bB}$ \\
\hline 40 & $6,75 \mathrm{bC}$ & $12,06 \mathrm{bB}$ & $17,75 \mathrm{bA}$ \\
\hline 60 & $16,13 \mathrm{aAB}$ & $13,31 \mathrm{bB}$ & $18,25 \mathrm{bA}$ \\
\hline \multirow[t]{2}{*}{ CV $(\%)$} & \multicolumn{3}{|c|}{15,18} \\
\hline & \multicolumn{3}{|c|}{$\operatorname{Mg}\left(\mathrm{g} \mathrm{kg}^{-1}\right)$} \\
\hline 0 & $3,50 \mathrm{cB}$ & $4,13 \mathrm{aB}$ & $10,38 \mathrm{cA}$ \\
\hline 20 & $6,75 \mathrm{bB}$ & $6,31 \mathrm{aB}$ & $13,88 \mathrm{bA}$ \\
\hline 40 & $7,38 \mathrm{bB}$ & $5,36 \mathrm{aB}$ & $17,39 \mathrm{aA}$ \\
\hline 60 & $10,75 \mathrm{aB}$ & $5,54 \mathrm{aC}$ & $18,13 \mathrm{aA}$ \\
\hline \multirow[t]{2}{*}{$\mathrm{CV}(\%)$} & \multicolumn{3}{|c|}{15,55} \\
\hline & \multicolumn{3}{|c|}{$\mathrm{S}\left(\mathrm{g} \mathrm{kg}^{-1}\right)$} \\
\hline 0 & $1,71 \mathrm{bB}$ & $2,39 \mathrm{aA}$ & $1,39 \mathrm{aB}$ \\
\hline 20 & $2,31 \mathrm{aA}$ & $2,55 \mathrm{aA}$ & $1,62 \mathrm{aB}$ \\
\hline 40 & $2,41 \mathrm{aA}$ & $1,57 \mathrm{bB}$ & $1,87 \mathrm{aB}$ \\
\hline 60 & $2,78 \mathrm{aA}$ & $1,99 \mathrm{abB}$ & $1,74 \mathrm{aB}$ \\
\hline CV (\%) & \multicolumn{3}{|c|}{15,00} \\
\hline
\end{tabular}

*Médias seguidas pela mesma letra, maiúsculas (nas linhas) e minúsculas (nas colunas), não diferem entre sí, pelo teste de Tukey, a 0,05 de probabilidade. 


\section{CONCLUSÕES}

1-O esterco de ovino e o húmus de minhoca são as fontes orgânicas que proporcionam os mais altos valores médios para as características morfológicas avaliadas.

2-A proporção de $40 \%$ do material orgânico, independentemente da fonte orgânica adicionada ao substrato, favoreceu o crescimento das mudas de goiabeira.

3-Proporções crescentes das fontes orgânicas no substrato provocam redução no teor de fósforo.

\section{REFERÊNCIAS}

BERNARDI, A. C. de C.; CARMELLO, Q.A. de C.; CARVALHO, S.A. de. Macronutrientes em mudas de citros cultivadas em vasos em resposta à adubação NPK. Revista Scientia Agrícola, Piracicaba, v. 57, n. 4, p. 761-767, 2000.

CASAGRANDE JÚNIOR, J.G.; VOLTOLINI, J.A.; HOFFMANN, A.; FACHINELLO, J.C. Efeito de materiais orgânicos no crescimento de mudas de araçazeiro (Psidium cattleyanum Sabine). Revista Brasileira de Agrociência, Pelotas, v.2, n. 3, p. 187-191, 1996

CHAVES, L. H. G.; DIAS, M. M. Formas de potássio em regossolos do estado da Paraíba. Pesquisa Agropecuária Brasileira, Brasília, v. 31, n. 7, p. 523-528, 1996.

CORREIA, D.; RIBEIRO, E.M.; LOPES, L.S.; ROSSETTI, A.G.; MARCO, C.A. Efeito de substratos na formação de porta-enxertos de Psidium guajava L. cv. Ogawa em tubetes. Revista Brasileira de Fruticultura, Jaboticabal, v. 27, n. 1, p. 88-91, 2005.

COSTA, A.M.G.; COSTA, J.T.A.; CAVALCANTI JÚNIOR, A.T.; CORREIA, D.; MEDEIROS FILHO, S. Influência de diferentes combinações de substratos na formação de porta-enxertos de gravioleira (Annoma muricata L.). Revista Ciência Agronômica, Fortaleza, v. 36, n. 3, p. 299-305, 2005.

CUNHA, A.O.; ANDRADE, L.A.de; BRUNO, R.L.A.; SILVA, J.A.L. da; SOUZA, V.C. de. Efeitos de substratos e das dimensões dos recipientes na qualidade das mudas de Tabebuia impetiginosa (Mart. Ex. D.C.) Standl. Revista Árvore, Viçosa, MG, v. 29, n. 4, p. 507-516, 2005.
DIAS, R.; MELO, B. de. RUFINO, M. de A.; SILVEIRA, D.L.; MORAIS, T.P. de. SANTANA, D.G. de. Fontes e proporção de material orgânico para a produção de mudas de cafeeiro em tubetes. Revista Ciência e Agrotecnologia, Lavras, v. 33, n. 3, p. 758-764, 2009.

FERREIRA, D.F. Análise estatística por meio do SISVAR (Sistema para Análise de Variância) para Windows versão 4.0. In: REUNIÃO ANUAL DA REGIÃO BRASILEIRA DA SOCIEDADE INTERNACIONAL DE BIOMETRIA, 45., 2000, São Carlos. Anais... São Carlos: UFSCar, 2000. p. 255-258.

FRANCO, C.F.; PRADO, R. de M.; BRACHIROLLI, L.F.; ROZANE, D.E. Curva de crescimento e marcha de absorção de macronutrientes em mudas de goiabeira. Revista Brasileira de Ciência do Solo, Viçosa, MG, v. 31, n. 6, p. 1429-1437, 2007.

GÓES, G.B. de; DANTAS, D.J.; ARAÚJO, W.B.M. de; MELO, I.G.C.; MENDONÇA, V. Utilização de húmus de minhoca como substrato na produção de mudas de tamarindeiro. Revista Verde de Agroecologia e Desenvolvimento Sustentável, Mossoró, v. 6, n. 4, p. 125-131, 2011.

LIMA, R. de L.S. de; SIQUEIRA, D.L. de; WEBER, O.B.; CECON, P.R. Teores de macronutrientes em mudas de aceroleira (Malpighia emarginata DC.) em função da composição do substrato. Revista Ciência e Agrotecnologia, Lavras, v. 30, n. 6, p. 1110-1115, 2006.

LIMA, R. de L.S. de; WEBER, O.B.; PEREIRA, W.E.; CORREIA, D.; SOFIATTI, V.; BRANDÃO, Z.N.; FERREIRA, G.B. Crescimento e teores de nutrientes em mudas de gravioleira cultivadas em seis substratos. Revista de Engenharia Ambiental, Espírito Santo do Pinhal, v. 6, n. 3, p. 594-606, 2009.

MENDONÇA, V.; ARAÚJO NETO, S.E. de; RAMOS, J.D.; PIO, R.; GONTIJO, T.C.A. Diferentes substratos e recipientes na formação de mudas de mamoeiro "Sunrise Solo". Revista Brasileira de Fruticultura, Jaboticabal, v. 25, n. 1, p. 127-130, 2003.

MESQUITA, E.F. de; CHAVES, L.H.G.; FREITAS, B.V.; SILVA, G.A.; SOUSA, M.V.R.; ANDRADE, R. Produção de mudas de mamoeiro em função de substratos contendo esterco bovino e volumes de recipientes. Revista Brasileira de Ciências Agrárias, Recife, v. 7, n. 1, p. 58-65, 2012. 
NEGREIROS, J. R. S.; BRAGA, L. R.; ÁLVARES, V. S.; BRUCKNER, C. H. Influência de substratos na formação de porta-enxerto de gravioleira (Annona muricata L.). Revista Ciência e Agrotecnologia, Lavras, v. 28, n. 3, p. 530-536, 2004.

PEREIRA, P.C.; MELO, B. de; FREITAS, R.S. de; TOMAZ, M.A.; FREITAS, C. de J.P. Mudas de tamarindeiro produzidas em diferentes níveis de matéria orgânica adicionada ao substrato. Revista Verde de Agroecologia e Desenvolvimento Sustentável, Mossoró, v. 5, n. 3, p. 152-159, jul.set. 2010.

PINTO, J.L. de B.; TAVARES, J.C.; ARAÚJO NETO, A.J. de. FREITAS, R. da S. de. RODRIGUES, G.S.de O. Efeito de diferentes substratos na formação de mudas de goiabeira. Revista Verde de Agroecologia e Desenvolvimento Sustentável, Mossoró, v. 2, n. 1, p. 127-134, 2007.

SAMARÃO, S.S.; MARTINS, M.A. Influência de fungos micorrízicos arbusculares, associada à aplicação de rutina, no crescimento de mudas de goiabeira (Psidium guajava L.). Revista Brasileira de Fruticultura, Jaboticabal, v. 21, n. 2, p. 196-199, 1999.
TOSTA, M. da S.; LEITE, G.A.; GÓES, G.B.de; MEDEIROS, P.V.Q. de; ALENCAR, R.D.; TOSTA, P. de A.F. Doses e fontes de matéria orgânica no desenvolvimento inicial de mudas de melancia "Mickylee". Revista Verde de Agroecologia e desenvolvimento Sustentável, Mossoró, v. 5, n. 2 , p. $117-122,2010$.

TRINDADE, A.V.; FARIA, N.G.; ALMEIDA, F.P. de. Uso de esterco no desenvolvimento de mudas de mamoeiro colonizados com fungos micorrízicos. Pesquisa Agropecuária Brasileira, Brasília, v. 35 , n. 7, p. 1389-1394, 2000.

ZIETEMANN, C.; ROBERTO, S.R. Produção de mudas de goiabeira (Psidium guajava L.) em diferentes substratos. Revista Brasileira de Fruticultura, Jaboticabal, v. 29, n. 1, p. 137-142, 2007. 